\title{
The COVID-19 pandemic and kangaroo mother care: What should we do?
}

\author{
Sevil Hakimi ${ }^{1}$
}

Kangaroo mother care (KMC) is a model of care that is an alternative to the incubator for preterm newborns. The World Health Organization (WHO) has recommended this type of care in both developed and developing countries as soon as the premature neonate is clinically stabilized ${ }^{1}$.

The COVID-19 pandemic originated in the Hubei province of China in December $2019^{2}$. The virus spread rapidly and by March 2020 over 100 countries were affected ${ }^{3}$. Owing to the high contagion and fatality rate of the virus and the WHO declaration of COVID-19 as a pandemic, routine medical care was impacted and consequently the rate of KMC may have also suffered.

Clinical evidence shows KMC could be effective in improving the newborn's neurodevelopment outcomes, stabilize preterm newborn's physiological function and decrease maternal distress following the birth. $\mathrm{KMC}$ is effective in the initiation of exclusive breastfeeding ${ }^{4}$. Human milk is a unique dynamic nutrition source for the newborn during the first 6 months of life. Human milk directly contributes to innate immunity of the newborn by shaping gut microbiota and milk oligosaccharides ${ }^{5}$.

Recently, the WHO recommended that mothers and newborns should not be separated. The dyads should enable the practice of KMC even in cases of suspected or confirmed COVID-19 by using personal protective equipment and the disinfection of used surfaces ${ }^{6}$.

We urge clinicians, midwives and policy makers to keep neonatal care at the frontline ${ }^{7}$, and as such consider KMC in the neonatal wards, with the use of all related precautions.

\section{REFERENGES}

1. World Health Organization. WHO recommendations on newborn health: guidelines approved by the WHO Guidelines Review Committee. https:// apps.who.int/iris/bitstream/handle/10665/259269/WHO-MCA-17.07-eng. pdf; jsessionid=121F5989F4EF8008CBA7D1C897B6OF4C? sequence $=1$. Updated May 2017. Accessed April 23, 2020.

2. Liu Y, Gayle AA, Wilder-Smith A, Rocklöv J. The reproductive number of COVID-19 is higher compared to SARS coronavirus. J Travel Med. 2020;27(2). doi:10.1093/jtm/taaaO21

3. Mao R, Liang J, Shen J, et al. Implications of COVID-19 for patients with preexisting digestive diseases. Lancet Gastroenterol Hepatol. 2020;5(5):426-428. doi:10.1016/S2468-1253(20)30076-5

4. Chan GJ, Labar AS, Wall S, Atun R. Kangaroo mother care: a systematic review of barriers and enablers. Bull World Health Organ. 2016;94(2):130-141. doi:10.2471/blt.15.157818

5. Cacho NT, Lawrence RM. Innate immunity and breast milk. Front Immunol. 2017;8:584. doi:10.3389/fimmu.2017.00584

6. World Health Organization. Clinical management of severe acute respiratory infection (SARI) when COVID-19 disease is suspected. https://www.who.int/publicationsdetail/clinical-management-of-severe-acute-respiratory-infection-when-novelcoronavirus-(ncov)-infection-is-suspected. Published March 13, 2020. Accessed

\section{AFFILIATION}

1 Department of Midwifery, Tabriz University of Medical Science, Tabriz, Iran

\section{CORRESPONDENCE TO}

Sevil Hakimi. Department of Midwifery, Tabriz University of Medical Science, Tabriz, Iran.

E-mail: hakimis@tbzmed.ac.ir

\section{KEYWORDS}

kangaroo mother care, COVID-19

Received: 23 April 2020 Accepted: 28 April 2020 
April 23, 2020.

7. Vivilaki VG, Asimaki E. Respectful midwifery care during the COVID-19 pandemic. Eur J Midwifery. 2020;4(April). doi:10.18332/ejm/120070

\section{CONFLICTS OF INTEREST}

The author has completed and submitted the ICMJE Form for Disclosure of Potential Conflicts of Interest and none was reported.

\section{FUNDING}

There was no source of funding for this research.

\section{PROVENANGE AND PEER REVIEW}

Not commissioned; internally peer reviewed. 